Article

\title{
Well-Defined Polypropylene/Polypropylene-Grafted Silica Nanocomposites: Roles of Number and Molecular Weight of Grafted Chains on Mechanistic Reinforcement
}

\author{
Masahito Toyonaga, Patchanee Chammingkwan, Minoru Terano and Toshiaki Taniike * \\ School of Materials Science, Japan Advanced Institute of Science and Technology, 1-1 Asahidai, Nomi, \\ Ishikawa 923-1292, Japan; toyonaga@tei-c.com (M.T.); chamming@jaist.ac.jp (P.C.); terano@jaist.ac.jp (M.T.) \\ * Correspondence: taniike@jaist.ac.jp; Tel.: +81-761-51-1630 \\ Academic Editor: Walter Remo Caseri \\ Received: 4 June 2016; Accepted: 9 August 2016; Published: 12 August 2016
}

\begin{abstract}
Grafting terminally functionalized polypropylene (PP) to nanofillers provides well-defined PP-based nanocomposites plausibly featured with a physical cross-linkage structure. In this paper, a series of PP-grafted silica nanoparticles $\left(\mathrm{PP}-g-\mathrm{SiO}_{2}\right)$ were synthesized by varying the number of grafted chains per silica particle, and influences of the number and the molecular weight of grafted chains were studied on physical properties of $\mathrm{PP} / \mathrm{PP}-\mathrm{g}-\mathrm{SiO}_{2}$ nanocomposites. We found that only 20-30 chain/particle was sufficient to exploit benefits of the PP grafting for the nanoparticle dispersion, the nucleation, and the Young's modulus. Meanwhile, the yield strength was sensitive to both of the number and the molecular weight of grafted PP: Grafting longer chains at a higher density led to greater reinforcement.
\end{abstract}

Keywords: polypropylene; nanocomposite; grafting technique; polymer-grafted nanofiller; co-crystallization; physical cross-linkage; mechanical properties; tensile test; materials design

\section{Introduction}

Growing production and applications of polymer materials have owed much to a variety of compounding technologies. In particular, polymer nanocomposites are one of the most promising materials, where the inclusion of nanosized fillers in polymer matrices can improve (or endow) a variety of properties including mechanical [1-4], thermal [5,6], flame retardant $[7,8]$, electric [9,10], electromagnetic [11,12], optical [13,14], barrier [15,16], and other properties [17-20]. Numerous researches have been implemented for each different combination of polymer and nanofillers. Among these, polypropylene (PP)-based nanocomposites have attracted particular attention, owing to the hugest market of PP and a multitude of potential applications [21].

The key issue for formulating PP-based nanocomposites is how to overcome poor compatibility and weak interfacial bonding arising from the chemical inertness of PP. The former is relevant to the dispersion of nanofillers in PP matrices, while the latter is important for load transfer to nanofillers [22] and durability against failures $[23,24]$. The compatibility problem is relatively easily solved through the addition of a compatibilizer such as maleic anhydride-grafted PP and organic modification of filler surfaces typically using silane coupling agents. Even without dispersants, in-situ methods can facilitate forcibly dispersed nanofillers, which include propylene polymerization in the presence of catalyst-bearing nanofillers $[25,26]$ and synthesis of nanoparticles from molecular precursors in molten PP $[27,28]$.

For strengthening the interfacial bonding, the most effective strategy is the polymer grafting. Polymer chains grafted onto filler surfaces not only aid the compatibilization of nanofillers but also 
entangle/interdiffuse with matrix polymer [29-35]. It is known that polymer chains grafted at their chain end offer much better interfacial reinforcement as compared to those grafted at their side chains [36]. This is because side-functionalized polymer chains wrap nanofillers and form a soft interfacial layer between PP and nanofillers, which hampers the hardness of nanofillers.

While many kinds of polymer have been grafted to nanofillers for PP nanocomposites [37-42], our recent efforts are regarded as one of a few successful examples that have employed terminally functionalized PP chains grafted to nanofillers [43,44]. In detail, terminally hydroxylated isotactic PP (PP-t-OH) with well-defined primary structures was grafted to silica $\left(\mathrm{SiO}_{2}\right)$ nanoparticles, and thus obtained PP-grafted $\mathrm{SiO}_{2}\left(\mathrm{PP}-\mathrm{g}-\mathrm{SiO}_{2}\right)$ nanoparticles were melt mixed with PP. We found several positive consequences of the PP grafting on boosting physical properties of resultant nanocomposites: Good dispersion up to $10 \mathrm{wt} \%$, at maximum 4 times faster crystallization compared with pristine PP, and approximately $+30 \%$ improvement in the Young's modulus and yield strength. Especially, the $+30 \%$ improvement of the yield strength was unexpectedly large as for spherical fillers of low aspect ratios. Terminally grafted PP chains worked as crystallization nuclei and co-crystallized with matrix PP. It was envisaged that $\mathrm{PP}-\mathrm{g}-\mathrm{SiO}_{2}$ would bridge neighboring lamellae through the co-crystallization and thus formed physical cross-linkage structure would be responsible for the unexpected reinforcement (Figure 1). In line with the above expectation, the nanocomposites completely lost the anomalous reinforcement when the lamellae were dissolved in a molten state.

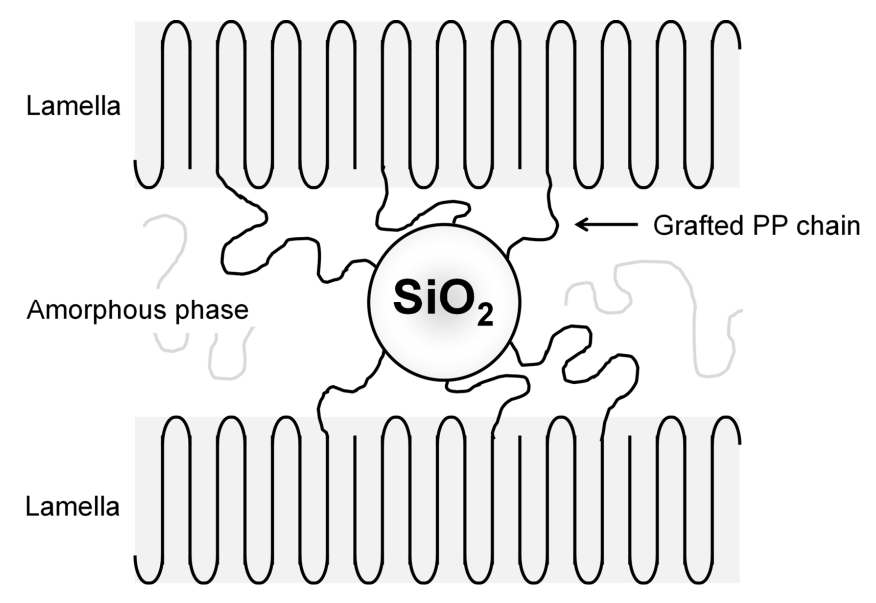

Figure 1. Schematic illustration of a physical cross-linkage structure for polypropylene (PP)/PP-grafted $\mathrm{SiO}_{2}\left(\mathrm{PP}-\mathrm{g}-\mathrm{SiO}_{2}\right)$ nanocomposites.

Based on our previous results [44], the maximum tensile reinforcement was achieved over a critical molecular weight of $1.2 \times 10^{4}$ for PP-t-OH grafted to $\mathrm{SiO}_{2}$ nanoparticles. In this report, we have systematically varied the number of grafted PP chains per $\mathrm{SiO}_{2}$ nanoparticle, and attempted to separately study impacts of the molecular weight and the number of the grafted chains on physical properties of $\mathrm{PP} / \mathrm{PP}-\mathrm{g}-\mathrm{SiO}_{2}$ nanocomposites. As long as we recognize, such a comprehensive study on the design of polymer-grafted nanoparticles for polymer nanocomposites has been limited to polystyrene that can be relatively easily controlled $[32,45,46]$, and rarely performed for PP that necessitates end functionalization during catalyzed olefin polymerization.

\section{Materials and Methods}

\subsection{Materials}

PP pellets $\left(M_{\mathrm{n}}=4.6 \times 10^{4}, M_{\mathrm{w}} / M_{\mathrm{n}}=5.65, \mathrm{mmmm}=98 \mathrm{~mol} \%\right)$ were donated from Japan Polypropylene Corporation. Propylene gas of research grade (Japan Polypropylene Corporation, Tokyo, Japan) was used as delivered. rac-Ethylenebis(1-indenyl)zirconium dichloride ( $\mathrm{EBIZrCl}_{2}$, metallocene catalyst) was purchased from Kanto Chemical Co., Inc. (Tokyo, Japan). Triethylaluminum 
(TEA, chain transfer agent) and modified methylaluminoxane (MMAO, activator) were donated by Tosoh Finechem Corporation (Shunan, Japan). Toluene and $n$-tetradecane were dried over molecular sieve $4 \mathrm{~A}$ followed by $\mathrm{N}_{2}$ bubbling. $\mathrm{SiO}_{2}$ nanoparticles with an average diameter of $26 \mathrm{~nm}$ and a surface area of $110 \mathrm{~m}^{2} / \mathrm{g}$ (Kanto Chemical Co., Inc.) were dried at $160^{\circ} \mathrm{C}$ for $4 \mathrm{~h}$ prior to the grafting reaction.

\subsection{Synthesis of Hydroxylated Isotactic Polypropylene (PP-t-OH)}

PP-t-OH was prepared according to literature [44]. Briefly, $300 \mathrm{~mL}$ of dried toluene, $4.5 \mathrm{mmol}$ of $\mathrm{MMAO}, 1.5 \mu \mathrm{mol}$ of $\mathrm{EBIZrCl}_{2}$, and $9.0 \mathrm{mmol}$ of TEA were charged in a stirred flask maintained at $0{ }^{\circ} \mathrm{C}$. Propylene polymerization was conducted at $0{ }^{\circ} \mathrm{C}$ by supplying $1 \mathrm{~atm}$ of propylene for $1 \mathrm{~h}$. The activator (MMAO) alkylates the catalyst precursor $\left(\mathrm{EBIZrCl}_{2}\right)$ and extracts an alkyl anion to form cationic active species $\left(\mathrm{EBIZrR}^{+}\right)$. To the formed active species, propylene monomer is coordinated and inserted to cause the chain growth. The chain growth is terminated through chain transfer reactions such as $\beta$-hydride elimination, chain transfer to monomer, and that to alkylaluminum. The former two chain transfer pathways bear terminally unsaturated PP, while the last one produces PP-t-Al. TEA works as a chain transfer agent to form PP-t-Al, whose concentration controls the molecular weight of the produced PP via chain transfer frequency. The low polymerization temperature was important to suppress the undesired chain transfer reactions. The polymerization product was reacted with $25 \mathrm{~mL}$ of $35 \mathrm{~mol} \%$ aqueous $\mathrm{H}_{2} \mathrm{O}_{2}$ under oxygen atmosphere at $0{ }^{\circ} \mathrm{C}$ for $1 \mathrm{~h}$, and subsequently hydrolyzed with methanol for $30 \mathrm{~min}$. These post-polymerization treatments convert (a majority of) PP- $t-\mathrm{Al}$ into PP-t-O-O-Al and eventually into PP- $t-\mathrm{OH}[47,48]$. The product was purified by repetitive washing with acidic ethanol and subsequent vacuum drying prior to characterization.

The primary structure of PP-t-OH was characterized mainly based on ${ }^{13} \mathrm{C}\left\{{ }^{1} \mathrm{H}\right\}$ NMR (Bruker $400 \mathrm{MHz}$ operating at $100 \mathrm{MHz}$ ) at $120{ }^{\circ} \mathrm{C}$ using hexachloro-1,3-butadiene as a diluent and 1,1,2,2-tetrachloroethane- $d_{2}$ as an internal lock and reference. The analytical method for the obtained spectra was described elsewhere [47]. Briefly, the isotacticity of PP-t-OH was determined as $85 \mathrm{~mol} \%$ in $m m m m$, which was less than $98 \mathrm{~mol} \%$, but sufficiently isotactic for co-crystallization with the matrix PP (see Figure S2 in Reference [44]). Terminal groups of PP-t-OH consisted of methyl as chain heads and hydroxyl as chain ends. Their molar ratio derived the end functionalization ratio of $73 \mathrm{~mol} \%$ (i.e., $27 \mathrm{~mol} \%$ of chains were not functionalized). The molecular weight $\left(M_{n}\right)$ of PP-t-OH was evaluated as $1.2 \times 10^{4}$ based on the molar ratio between main chain carbons and terminal carbons. Owing to the narrow molecular weight distribution of metalloncene-catalyzed $\mathrm{PP}-\mathrm{t}-\mathrm{OH}$, the $M_{\mathrm{n}}$ values were quantitatively comparable between ${ }^{13} \mathrm{C}$ NMR and gel permeation chromatography [44].

\subsection{Synthesis of Polypropylene-Grafted $\mathrm{SiO}_{2}\left(\mathrm{PP}-\mathrm{g}-\mathrm{SiO}_{2}\right)$}

$\mathrm{PP}-t-\mathrm{OH}$ was grafted onto $\mathrm{SiO}_{2}$ nanoparticles via condensation between the terminal hydroxyl group of PP- $t-\mathrm{OH}$ and surface silanol groups of $\mathrm{SiO}_{2}$. A specified amount of PP-t-OH (0.1-4.0 g) and $0.5 \mathrm{~g}$ of $\mathrm{SiO}_{2}$ nanoparticles were reacted in tetradecane containing $0.1 \mathrm{~mol} / \mathrm{L}$ of 6-di-tert-butyl-p-cresol at $200{ }^{\circ} \mathrm{C}$ for $6 \mathrm{~h}$ under $\mathrm{N}_{2}$ and vigorous stirring. Unreacted polymer was carefully removed with repetitive hot filtration in $o$-dichlorobenzene at $140{ }^{\circ} \mathrm{C}$. The resultant particles were washed with methanol, and dried in vacuo at $60^{\circ} \mathrm{C}$ for $6 \mathrm{~h}$. It must be noted that PP-t-OH retained the capability of co-crystallization with the matrix PP even after being grafted (again see Figure S2 in Reference [44]).

\subsection{Synthesis of PP/PP-g-SiO ${ }_{2}$ Nanocomposites}

PP-based nanocomposites were prepared by a two-roll mixer at $20 \mathrm{rpm} .10 \mathrm{~g}$ of the PP pellets was kneaded at $185{ }^{\circ} \mathrm{C}$ for $5 \mathrm{~min}$, followed by the addition of a specified amount of unmodified $\mathrm{SiO}_{2}$ or $\mathrm{PP}-\mathrm{g}-\mathrm{SiO}_{2}$ nanoparticles $(0,1,3,5 \mathrm{wt} \%)$. The mixture was kneaded at $185^{\circ} \mathrm{C}$ for additional $10 \mathrm{~min}$. Sample films with the thickness of $200 \mu \mathrm{m}$ were prepared by hot press at $230^{\circ} \mathrm{C}$ and $20 \mathrm{MPa}$, followed by quenching at $100{ }^{\circ} \mathrm{C}$ for $5 \mathrm{~min}$. 


\subsection{Analyses}

Thermogravimetric analysis (TGA, METTLER TOLEDO TG50, Columbus, OH, USA) was employed to measure the amount of grafted polymer. The temperature was kept at $200{ }^{\circ} \mathrm{C}$ for $30 \mathrm{~min}$ to remove physisorbed water, and then increased up to $650{ }^{\circ} \mathrm{C}$ at $20^{\circ} \mathrm{C} / \mathrm{min}$. The grafted amount was estimated from the difference in the weight loss between $\mathrm{PP}-g-\mathrm{SiO}_{2}$ and unmodified $\mathrm{SiO}_{2}$ in the range of $200-650{ }^{\circ} \mathrm{C}$. The weight of grafted chains was converted into the chain number using $M_{n}$, while the number of nanoparticles in the unit gram of $\mathrm{SiO}_{2}$ was estimated from the weight of one nanoparticle with the sphere diameter of $26 \mathrm{~nm}$ and the density of $2.2 \mathrm{~g} / \mathrm{cm}^{3}$. Thus, the grafted amount was finally expressed in the unit of the chain number per particle. The dispersion of $\mathrm{SiO}_{2}$ nanoparticles was observed by a transmission electron microscope (TEM, Hitachi H-7100, Tokyo, Japan), using specimens with the thickness of $100 \mathrm{~nm}$, which were prepared by an ultramicrotome (Reichert Ultracut S with a FC-S cryoattachement, Leica Microsystems, Wetzlar, Germany). The crystallization behavior of PP was examined using differential scanning calorimetry (DSC, METTLER TOLEDO DSC 822, Columbus, $\mathrm{OH}$, USA). A sample was heated from room temperature to $200^{\circ} \mathrm{C}$ at $20^{\circ} \mathrm{C} / \mathrm{min}$, then kept at $200{ }^{\circ} \mathrm{C}$ for $5 \mathrm{~min}$ to eliminate the thermal history, and finally cooled down to $128^{\circ} \mathrm{C}$ at $20^{\circ} \mathrm{C} / \mathrm{min}$ for the isothermal crystallization. The endotherm in the first heat cycle was employed to aquire the melting point $\left(T_{\mathrm{m}}\right)$, the crystallinity $\left(X_{\mathrm{c}}\right)$, and the distribution of lamellar thickness $\left(l_{\mathrm{c}}\right)$ [49-52]. The isothermal crystallization rate (denoted as $t_{1 / 2}{ }^{-1}$ ) was defined as an inverse of the half time of the crystallization at $128^{\circ} \mathrm{C}$. Wide-angle X-ray diffraction (WAXD) measurements were performed in a reflection mode at room temperature with $\mathrm{Cu} K \alpha$ radiation operating at $40 \mathrm{kV}$ and $30 \mathrm{~mA}$. The scanning rate was $1^{\circ} / \mathrm{min}$ over $2 \theta$ of $10^{\circ}-30^{\circ}$. Tensile properties were measured by a tensile tester (Abe Dat-100, Kanazawa, Japan). A stress-strain curve was acquired at room temperature and at a crosshead speed of $1.0 \mathrm{~mm} / \mathrm{min}$. Tensile properties were calculated as the average of 5 measurements.

\section{Results and Discussion}

A list of PP-g-SiO 2 samples used in this study is summarized in Table 1. A part of the samples was taken from Reference [44] in order to separately discuss impacts of the amount and length of grafted PP chains on physical properties of resultant nanocomposites. When $667 \mu \mathrm{mol}$ of PP-t-OH was reacted with one gram of $\mathrm{SiO}_{2}$ nanoparticles in the grafting reaction, the amount of grafted PP chains always fell in the range of 10-11 wt \% irrespective of the molecular weight of PP-t-OH (except the shortest PP-t-OH with $M_{n}=5.8 \times 10^{3}$ ). This result was interpreted as follows: Grafted chains form polymer layer on $\mathrm{SiO}_{2}$ surfaces and make it increasingly difficult for ungraftd chains to reach bare surfaces. Since the thickness of the polymer layer is determined by the grafted amount rather than the molecular weight, the graftable amount became independent of the molecular weight, and thus the number of grafted chains per $\mathrm{SiO}_{2}$ nanoparticle decreases anti-proportionally to the molecular weight of PP-t-OH. By changing the ratio between the two reactants, PP- $t-\mathrm{OH}$ and $\mathrm{SiO}_{2}$ while fixing $M_{\mathrm{n}}$ of PP-t-OH at $1.2 \times 10^{4}$, the grafted amount was controlled from 2.2 to $11.4 \mathrm{wt} \%$, corresponding to 21 and 120 chain number per particle, respectively. The grafted amount increased in a convergent manner against the addition amount of PP-t-OH, in agreement with the above-explained self-limiting mechanism.

Nanocomposites were prepared by melt mixing 1-5 wt \% of $\mathrm{PP}-\mathrm{g}-\mathrm{SiO}{ }_{2}$. Figure 2 shows TEM micrographs for selected samples to evaluate the dispersion of the nanoparticles in the matrix. Unmodified $\mathrm{SiO}_{2}$ nanoparticles were relatively uniformly dispersed at $1.0 \mathrm{wt} \%$ (Figure 2a), but formed micron-sized compact aggregates at $5.0 \mathrm{wt} \%$ (Figure $2 \mathrm{~b}$ ). In contrast to unmodified $\mathrm{SiO}_{2}, \mathrm{PP}_{-} \mathrm{g}-\mathrm{SiO}_{2}$ showed uniform dispersion at $1-5 \mathrm{wt} \%$ (Figure $2 \mathrm{c}, \mathrm{d}$ ), and the dispersion was not deteriorated even when the chain number per particle was reduced to 21 (Figure $2 \mathrm{~d}, \mathrm{e}$ ). The chain number per particle of 21 corresponds to $0.01 \mathrm{chain} / \mathrm{nm}^{2}$, and a PP chain with $M_{\mathrm{w}}=2.4 \times 10^{4}$ (calculated from $M_{\mathrm{n}}=1.2 \times 10^{4}$ based on $M_{\mathrm{w}} / M_{\mathrm{n}}=2$ ) occupies $122 \mathrm{~nm}^{2} /$ chain at the random-coil state [53,54]. Multiplying 0.01 chain $/ \mathrm{nm}^{2}$ by $122 \mathrm{~nm}^{2} /$ chain leads to $121 \%$ coverage of $\mathrm{SiO}_{2}$ surfaces. In this way, it is estimated that $\mathrm{SiO}_{2}$ surfaces were fully covered by grafted PP even at 21 chain/particle, and the surface energy of $\mathrm{PP}-\mathrm{g}-\mathrm{SiO}_{2}$ was believed to be similar in the range of $21-120$ chain/particle, 
which plausibly explains uniform dispersion at 21 chain/particle. The coverage for $120 \mathrm{PP} 120-g-\mathrm{SiO}_{2}$ is similarly estimated as $692 \%$. Even with similar surface energies, the state of grafted chains must change from random-coil to brush-like as the coverage increases [45,46,54]. The coverage for 140PP58- $g$ - $\mathrm{SiO}_{2}$, $160 \mathrm{PP} 87-g-\mathrm{SiO}_{2}, 70 \mathrm{PP} 180-g-\mathrm{SiO}_{2}, 40 \mathrm{PP} 330-g-\mathrm{SiO}_{2}$, and $30 \mathrm{PP} 460-g-\mathrm{SiO}_{2}$ was respectively estimated as $358 \%, 644 \%, 636 \%, 716 \%$ and $779 \%$. Thus, it was believed that $\mathrm{SiO}_{2}$ nanoparticles were (almost) fully covered by grafted PP chains, offering similarly uniform dispersion.

Table 1. List of $\mathrm{PP}-\mathrm{g}-\mathrm{SiO}_{2}$ samples used in this study and their characteristics.

\begin{tabular}{|c|c|c|c|}
\hline Sample ${ }^{a}$ & $\begin{array}{c}\text { PP- } t-\mathrm{OH} \text { amount } \\
\left(\mu \mathrm{mol} \text { per gram of } \mathrm{SiO}_{2}\right)^{b}\end{array}$ & $\begin{array}{l}\text { Grafted amount } \\
\quad(w t \%)^{c}\end{array}$ & $\begin{array}{l}\text { Chain number } \\
\text { per particle } \\
\text { d }\end{array}$ \\
\hline $21 \mathrm{PP} 120-g-\mathrm{SiO}_{2}$ & 16.7 & 2.2 & 21 \\
\hline $65 \mathrm{PP} 120-g-\mathrm{SiO}_{2}$ & 83.3 & 6.3 & 65 \\
\hline $96 \mathrm{PP} 120-g-\mathrm{SiO}_{2}$ & 333 & 9.1 & 96 \\
\hline $120 \mathrm{PP} 120-g-\mathrm{SiO}_{2}$ & 667 & 11.4 & 120 \\
\hline $140 \mathrm{PP} 58-g-\mathrm{SiO}_{2}{ }^{\mathrm{e}}$ & 667 & 6.4 & 140 \\
\hline $160 \mathrm{PP} 87-g-\mathrm{SiO}_{2} \mathrm{e}$ & 667 & 10.7 & 160 \\
\hline $70 \mathrm{PP} 180-g-\mathrm{SiO}_{2}{ }^{\mathrm{e}}$ & 667 & 9.6 & 70 \\
\hline $40 \mathrm{PP} 330-g-\mathrm{SiO}_{2} \mathrm{e}$ & 667 & 10.4 & 40 \\
\hline $30 \mathrm{PP} 460-g-\mathrm{SiO}_{2} \mathrm{e}$ & 667 & 10.9 & 30 \\
\hline
\end{tabular}

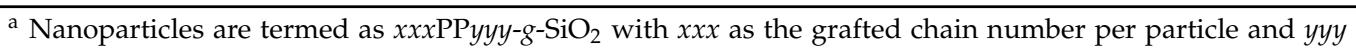
as $M_{n} / 100 ;{ }^{b}$ The amount of PP-t-OH used for the grafting reaction; ${ }^{c}$ Determined with TGA; ${ }^{d}$ The chain number per particle was estimated using $M_{n}$ of $\mathrm{PP}-t-\mathrm{OH}$, the measured grafted amount, and the number of $\mathrm{SiO}_{2}$ nanoparticles per gram. The last parameter was deduced from the specific surface area and the diameter of $\mathrm{SiO}_{2}$ nanoparticles (110 $\mathrm{m}^{2} / \mathrm{g}$ and $26 \mathrm{~nm}$, respectively); ${ }^{\mathrm{e}}$ Obtained from Reference [44].
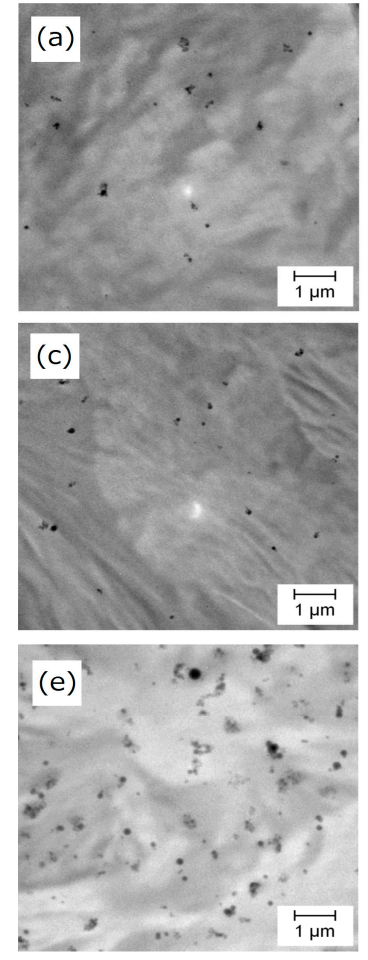
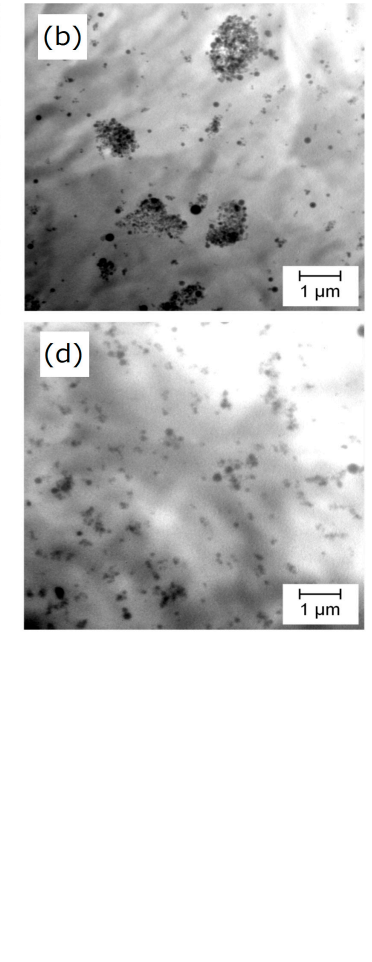

Figure 2. Transmission electron microscope (TEM) images for (a) $\mathrm{PP} / \mathrm{SiO}_{2}$ (1 wt \%); (b) $\mathrm{PP} / \mathrm{SiO}_{2}$ (5 wt \%); (c) PP/120PP120- $-\mathrm{S}-\mathrm{SiO}_{2}$ (1 wt \%); (d) PP/120PP120- $-\mathrm{S}-\mathrm{SiO}_{2}$ (5 wt \%), and (e) $\mathrm{PP} / 21 \mathrm{PP} 120-g-\mathrm{SiO}_{2}(5 \mathrm{wt} \%)$.

DSC results are summarized in Table 2, again referring to our previous data [44]. The addition of unmodified $\mathrm{SiO}_{2}$ and $\mathrm{PP}-\mathrm{g}-\mathrm{SiO}_{2}$ hardly affected the crystallinity, and the melting temperature seemed 
to be slightly lowered by $1-2{ }^{\circ} \mathrm{C}$. On the other hand, the PP grafting endows a nucleation ability to $\mathrm{SiO}_{2}$ nanoparticles, leading to marked enhancement in the crystallization rate. Figure $3 a$ plots the crystallization rate along the chain number per particle at the filler content of $5.0 \mathrm{wt} \%$. For comparison, our previous data for PP/PP- $g-\mathrm{SiO}_{2}$ nanocomposites [44] are also plotted. These nanocomposites contained $5.0 \mathrm{wt} \%$ of $\mathrm{PP}-\mathrm{g}-\mathrm{SiO}_{2}$ with different molecular weights of the grafted chains, where the chain number per particle decreased roughly anti-proportionally to the molecular weight. It was found that the crystallization rate followed similar correlation curves for the chain number per particle, irrespective of the way of its variation (i.e., either through the grafted amount or through the molecular weight). Most of the enhancement was achieved only with 20-30 chain/particle, and additional grafting resulted in small increments even though each grafted chain was regarded as a crystallization nucleus. This fact meant that the number of crystallites formable per particle is limited plausibly due to a steric reason. In Figure $3 b$, the crystallization rate was found to increase in proportion to the $\mathrm{PP}-\mathrm{g}-\mathrm{SiO}_{2}$ content. This fact indicated that the nanoparticles as crystallization nuclei dispersed similarly uniformly in the range of $1-5 \mathrm{wt} \%$.

Table 2. List of PP- $g-\mathrm{SiO}_{2}$ samples used in this study and their characteristics.

\begin{tabular}{cccc}
\hline Sample & $\boldsymbol{T}_{\mathbf{m}}\left({ }^{\circ} \mathbf{C}\right)^{\mathbf{a}}$ & $\boldsymbol{X}_{\mathbf{c}}(\mathbf{\%})^{\mathbf{a}}$ & $\boldsymbol{t}_{\mathbf{1 / 2}}{ }^{\mathbf{1}} \times \mathbf{1 0}^{\mathbf{2}} \mathbf{( \mathbf { 1 } / \mathbf { s } ) ^ { \mathbf { b } }}$ \\
\hline Pristine PP & 163 & 50 & 0.46 \\
$\mathrm{PP} / \mathrm{SiO}_{2}(1 \mathrm{wt} \%)$ & 160 & 49 & 0.48 \\
$\mathrm{PP} / \mathrm{SiO}_{2}(3 \mathrm{wt} \%)$ & 161 & 49 & 0.52 \\
$\mathrm{PP} / \mathrm{SiO}_{2}(5 \mathrm{wt} \%)$ & 162 & 47 & 0.51 \\
$\mathrm{PP} / 140 \mathrm{PP} 58-g-\mathrm{SiO}_{2}(5 \mathrm{wt} \%)^{\mathrm{c}}$ & 159 & 50 & 2.1 \\
$\mathrm{PP} / 140 \mathrm{PP} 87-g-\mathrm{SiO}_{2}(5 \mathrm{wt} \%)^{\mathrm{c}}$ & 162 & 51 & 1.8 \\
$\mathrm{PP} / 21 \mathrm{PP} 120-g-\mathrm{SiO}_{2}(5 \mathrm{wt} \%)$ & 163 & 51 & 1.3 \\
$\mathrm{PP} / 65 \mathrm{PP} 120-g-\mathrm{SiO}_{2}(5 \mathrm{wt} \%)$ & 162 & 51 & 1.5 \\
$\mathrm{PP} / 96 \mathrm{PP} 120-g-\mathrm{SiO}_{2}(5 \mathrm{wt} \%)$ & 161 & 52 & 1.4 \\
$\mathrm{PP} / 120 \mathrm{PP} 120-g-\mathrm{SiO}_{2}(1 \mathrm{wt} \%)$ & 161 & 50 & 0.90 \\
$\mathrm{PP} / 120 \mathrm{PP} 120-g-\mathrm{SiO}_{2}(3 \mathrm{wt} \%)$ & 162 & 49 & 1.4 \\
$\mathrm{PP} / 120 \mathrm{PP} 120-g-\mathrm{SiO}_{2}(5 \mathrm{wt} \%)$ & 160 & 51 & 1.7 \\
$\mathrm{PP} / 70 \mathrm{PP} 180-g-\mathrm{SiO}_{2}(5 \mathrm{wt} \%)^{\mathrm{c}}$ & 163 & 48 & 1.1 \\
$\mathrm{PP} / 40 \mathrm{PP} 330-\mathrm{SiO}_{2}(5 \mathrm{wt} \%)^{\mathrm{c}}$ & 162 & 51 & 1.4 \\
$\mathrm{PP} / 30 \mathrm{PP} 460-g-\mathrm{SiO}_{2}(5 \mathrm{wt} \%)^{\mathrm{c}}$ & 161 & 53 & 1.2 \\
\hline Obtained from the first heat cycle; ${ }^{\mathrm{b}}$ Isothermal crystallization at $128{ }^{\circ} \mathrm{C} ;{ }^{\mathrm{c}}$ Obtained from Reference [44].
\end{tabular}
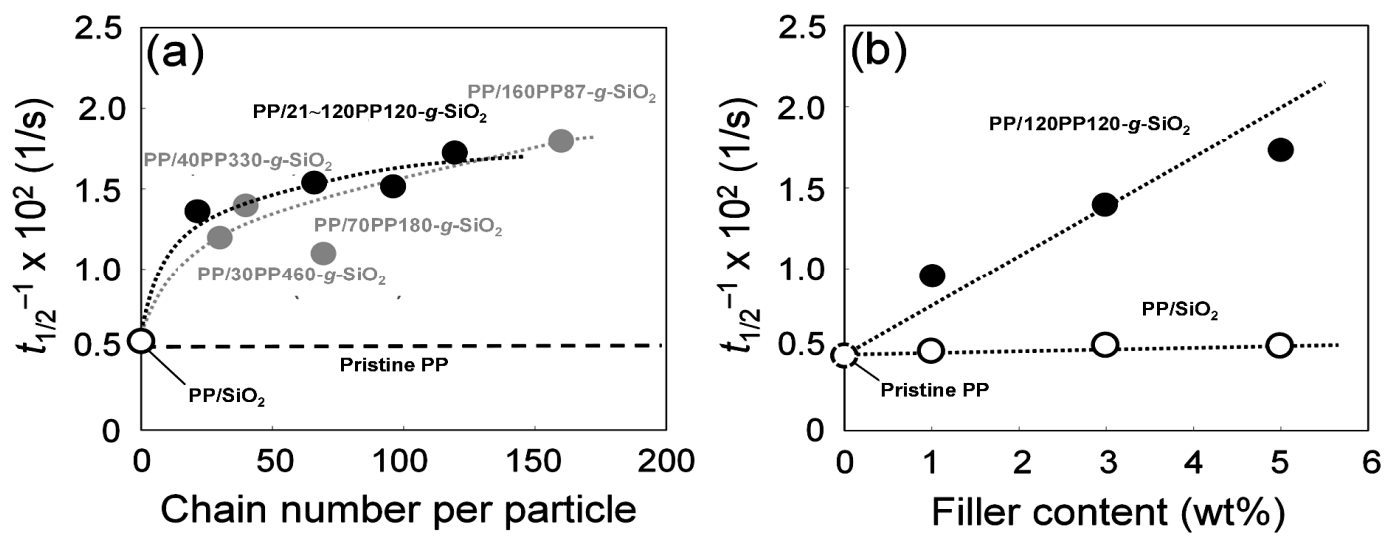

Figure 3. Variation of the crystallization rate at $128^{\circ} \mathrm{C}$ (a) along the chain number per particle at the fixed filler content $(5.0 \mathrm{wt} \%)$, and (b) along the filler content at the fixed chain number per particle (120 chain/particle): $(\circ, \bullet, \bullet) \mathrm{PP} / \mathrm{SiO}_{2}, \mathrm{PP} / x x x \mathrm{PP} 120-g-\mathrm{SiO}_{2}$, and $\mathrm{PP} / x x x \mathrm{PP} y y y-g-\mathrm{SiO}_{2}$. The data for $\mathrm{PP} / x x x \mathrm{PP} y y y-g-\mathrm{SiO}_{2}$ is taken from Reference [44]. 
As described above, the inclusion of $\mathrm{PP}-\mathrm{g}-\mathrm{SiO}_{2}$ nanoparticles did not affect the melting point and crystallinity of the matrix PP, while their nucleation ability might suggest potential influences on higher-order structures of the matrix. For instance, the formation of trans crystals on filler surfaces can be important in indentifying the origin of mechanical reinforcement [55]. Here, results of additional structural characterization are reported for $\mathrm{PP} / 120 \mathrm{PP} 120-\mathrm{g}-\mathrm{SiO}_{2}$ at $5.0 \mathrm{wt} \%$. Figure 4 compares WAXD patterns among pristine $\mathrm{PP}, \mathrm{PP} /$ unmodified $\mathrm{SiO}_{2}$, and $\mathrm{PP} / 120 \mathrm{PP} 120-g-\mathrm{SiO}_{2}$. All the samples showed typical characteristics of the $\alpha$-form, without any noticeable changes in the peak intensity ratio and the peak widths. Figure 5 displays the distribution of lamellar thickness $\left(l_{\mathrm{c}}\right)$ that was derived from the DSC endotherm in the first heating. For pristine PP, the lamellar thickness ranges from 8 to $21 \mathrm{~nm}$ with the peak top located at $16 \mathrm{~nm}$. The inclusion of unmodified $\mathrm{SiO}_{2}$ nanoparticles added a shoulder at about $13 \mathrm{~nm}$ to the original distribution. As observed in Figure 2b, the dispersion of unmodified $\mathrm{SiO}_{2}$ nanoparticles was highly non-uniform. A local high concentration of nanoparticles (agglomeration) confined the growth of lamellae [56,57]. In the case of $\mathrm{PP}-\mathrm{g}-\mathrm{SiO}_{2}$, the distribution was downward shifted with the new peak top located at $15 \mathrm{~nm}$. The dimensional reduction of the higher-order structure was reasonable as $\mathrm{PP}-g-\mathrm{SiO}_{2}$ nanoparticles offered the crystallization nuclei. Stern et al. reported that the tensile stress of pristine PP develops proportionally to the lamellar thickness [58]. Considering all of these facts, mechanical reinforcement in $\mathrm{PP} / \mathrm{PP}-\mathrm{g}-\mathrm{SiO}_{2}$ nanocomposites was hardly attributed to the alternation of higher-order structures by the addition of $\mathrm{PP}-\mathrm{g}-\mathrm{SiO}_{2}$. It must be noted that even though the addition of short alkyl chain-modified $\mathrm{SiO}_{2}$ nanoparticles causes similar consequences to higher-order structures of $\mathrm{PP}$, the extent of reinforcement is far less than that brought by $\mathrm{PP}-\mathrm{g}-\mathrm{SiO}_{2}[43]$.

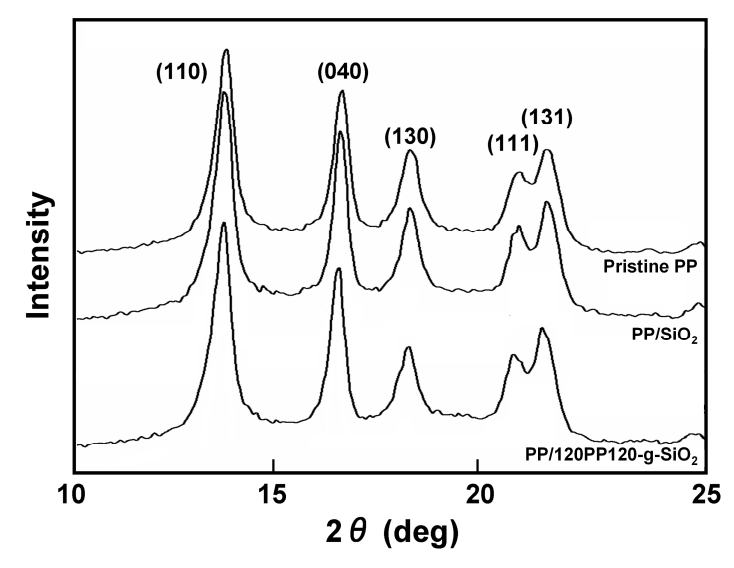

Figure 4. Wide-angle X-ray diffraction (WAXD) patterns.

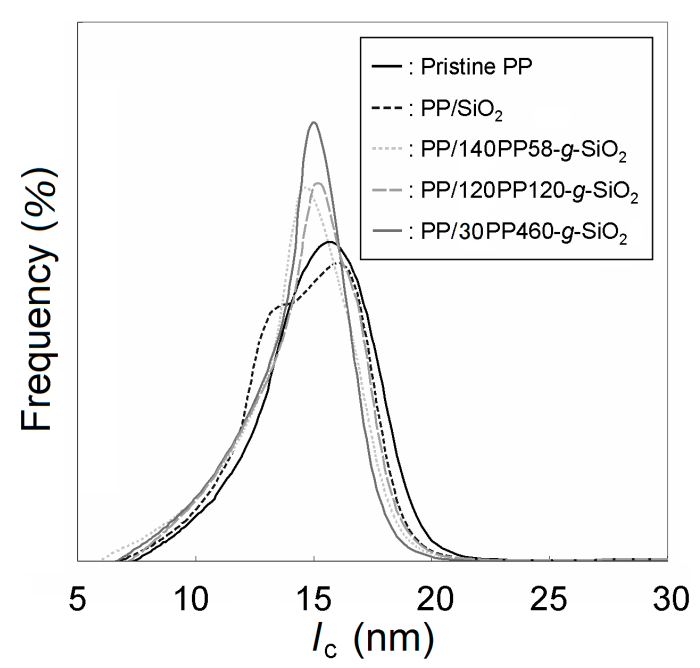

Figure 5. Lamellar thickness distribution acquired based on the DSC endotherm in the first heating. 
Uniaxial tensile properties of the prepared nanocomposites were investigated. Typical stress-strain curves are displayed in Figure 6. The addition of unmodified $\mathrm{SiO}_{2}$ hardly affected the stress development at a lower strain, leading to little improvement in the Young's modulus and yield stress. The addition of $\mathrm{PP}-\mathrm{g}-\mathrm{SiO}_{2}$ markedly enhanced these properties through the improved dispersion and interfacial bonding, which necessarily caused great reduction in the ductility at $5.0 \mathrm{wt} \%$.

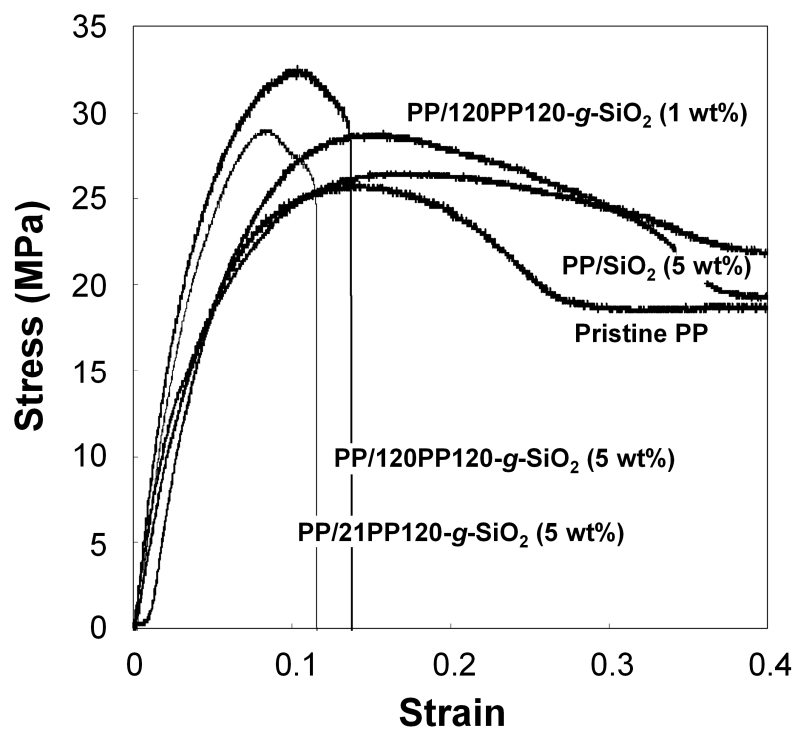

Figure 6. Stress-strain curves.

The Young's modulus, yield strength and elongation at break were calculated as average values among 5 specimens for each nanocomposite. Figure 7 plots the tensile properties of the nanocomposites at $5.0 \mathrm{wt} \%$ against the grafted chain number per particle. Again, our previous data with varied molecular weights of grafted chains are included for the sake of comparison. It was expected that not only the chain number per particle but also the molecular weight of grafted chains might contribute to the enhancement of the Young's modulus and yield strength, as both the factors enrich interfacial bonding and physical cross-linkage. For the Young's modulus, the reinforcement almost reached the maximum (around $+30 \%$ compared with that of pristine PP) at 21 chain/particle, and further grafting hardly improved it. It was also observed that the molecular weight of the grafted chains hardly affected the extent of the reinforcement. García et al. succeeded to disperse colloidal $\mathrm{SiO}_{2}$ nanoparticles in PP without any chemical modification or additives, and achieved $+30 \%$ reinforcement of the Young's modulus compared with pristine PP [59]. This fact suggested that uniform dispersion of hard nanoparticles is sufficient to improve the Young's modulus and the interfacial bonding is unnecessary, which is in line with our previous findings that the modulus was insensitive to the details of grafted chains [44].

Differently from the Young's modulus, the yield strength was greatly dependent on the chain number per particle (Figure $7 \mathrm{~b}$ ). While the increment from 0 to 21 chain/particle was the greatest (since the dispersion improvement also contributed), further grafting led to monotonous reinforcement of the yield strength and finally reached $+27 \%$ reinforcement at 120 chain/particle compared with pristine PP. The increment in the molecular weight of grafted chains also led to enhanced reinforcement in spite of the reduction in the chain number per particle. Thus, it was clear that both the chain number and the molecular weight of grafted chains are critical for the improvement of the yield strength. The maximum reinforcement over pristine PP has reached $+30 \%$ which was unexpectedly high for the inclusion of spherical nanoparticles. Such anomalous reinforcement in the yield strength had been attributed to a physical cross-linkage structure (Figure 1), in which $\mathrm{PP}-\mathrm{g}-\mathrm{SiO}_{2}$ bridges matrix lamellae with a fraction of grafted chains involved in the lamellae through co-crystallization [44]. Combination between 
the great reinforcement in the solid state and scarce improvement of shear modulus in the molten state had supported the above hypothesis in an analogous fashion to thermoelastomer [60]. In such a viewpoint, it was believed that the observed sensitivity of the yield strength on the density and molecular weight of grafted chains was relevant to the extent of the physical cross-linkage, i.e., a chance of the cross-linkage must enhance as the density and molecular weight of grafted chains increase. The elongation at break was dramatically reduced in the presence of grafted chains, plausibly due to the restricted deformation via a physical cross-linkage structure.

Influences of the filler content were also examined. All of the properties varied nearly proportionally to the filler content, which again suggested that the dispersion of $\mathrm{PP}-\mathrm{g}-\mathrm{SiO}_{2}$ was unaltered in the range of $1-5 \mathrm{wt} \%$, and that the tensile reinforcement of the matrix was originated from $\mathrm{PP}-\mathrm{g}-\mathrm{SiO}_{2}$ nanoparticles.

In summary, the PP grafting caused both reinforcement and embrittlement of the nanocomposites. Interface design through the chain number and molecular weight of the grafted chains was critical for the yield strength, but not for the other properties. Except the ductility, the best nanocomposite with a physical cross-linkage structure was obtained at the highest filler content (as long as good dispersion is retained), and with the greatest chain number per particle and the highest molecular weight of the grafted chains.
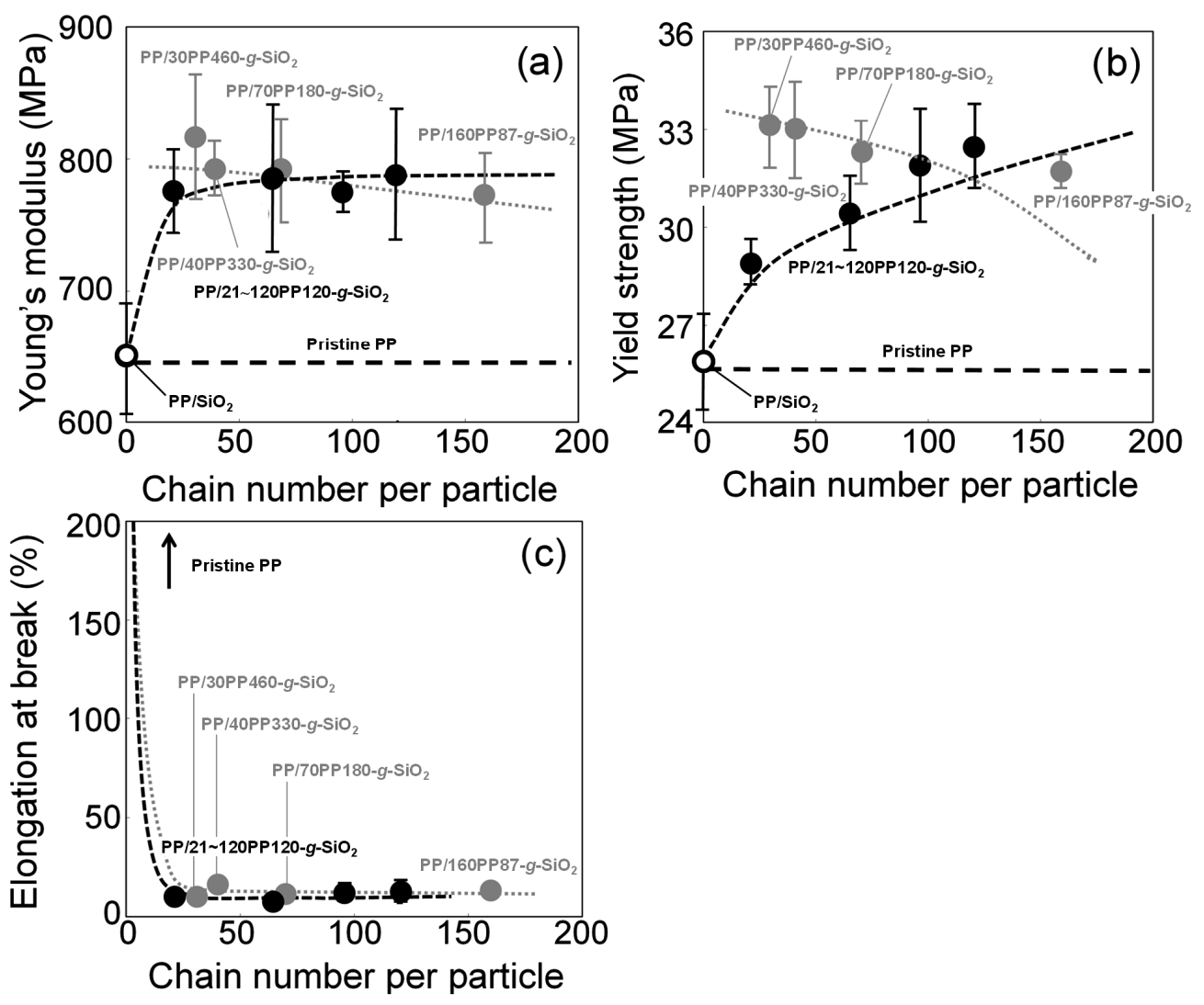

Figure 7. Tensile properties as a function of the chain number per particle: (a) Young's modulus; (b) yield strength; and (c) elongation at break. The symbols $(0, \bullet, \bullet)$ correspond to $\mathrm{PP} / \mathrm{SiO}_{2}$, $\mathrm{PP} / x x x \mathrm{PP} 120-g-\mathrm{SiO}_{2}$, and $\mathrm{PP} / x x x \mathrm{PP} y y y-g-\mathrm{SiO}_{2}$, respectively. The data for $\mathrm{PP} / x x x \mathrm{PP} y y y-g-\mathrm{SiO}_{2}$ is taken from Reference [44].

\section{Conclusions}

$\mathrm{PP} / \mathrm{PP}-\mathrm{g}-\mathrm{SiO}_{2}$ nanocomposites featured with a physical cross-linkage structure offer a multitude of advantages such as uniform dispersion of nanoparticles, accelerated crystallization, and great tensile reinforcement. Starting from $\mathrm{PP}-t-\mathrm{OH}$ with well-defined primary structures, a series of $\mathrm{PP}-g-\mathrm{SiO}_{2}$ 
nanoparticles were synthesized, and materials design for $\mathrm{PP}-\mathrm{g}-\mathrm{SiO}_{2}$ was comprehensively studied on physical properties of $\mathrm{PP} / \mathrm{PP}-\mathrm{g}-\mathrm{SiO}_{2}$ nanocomposites. The findings are summarized below.

1. As long as filler surfaces are mostly covered by grafted chains, the number of grafted chains per particle is not important for improving the dispersion of nanoparticles. 21 chain/particle (corresponding to $120 \%$ coverage) was sufficient in our system.

2. The presence of grafted chains is essential to endow a nucleating ability to $\mathrm{SiO}_{2}$ nanoparticles. The density of dispersed PP- $g-\mathrm{SiO}_{2}$ nanoparticles in PP is important to enhance the crystallization rate, rather than the number of grafted chains.

3. The Young's modulus is not sensitive to the interfacial bonding as long as nanoparticles are well dispersed. Meanwhile, both the number and the molecular weight of grafted chains are crucial for improving the yield strength.

In the end, the significance of the synthetic controls must be noted in realizing such a comprehensive study with reliable conclusions on PP-based nanocomposites. Especially, functionalization in metallocene-catalyzed olefin polymerization and complete removal of ungrafted chains by repetitive washing were essential for the well-defined nature of the study. On the other hand, these processes were far inefficient to be industrially viable. It is expected that the obtained conclusions would be embodied within improved synthetic strategies.

Acknowledgments: The authors appreciate Japan Polypropylene Corporation and Tosoh Finechem Corporation for the reagent donation.

Author Contributions: Masahito Toyonaga performed experiments and wrote the paper. Patchanee Chammingkwan analyzed the obtained data. Minoru Terano and Toshiaki Taniike supervised the research and revised the paper.

Conflicts of Interest: The authors declare no conflict of interest.

\section{References}

1. Usuki, A.; Kawasumi, M.; Kojima, Y.; Fukushima, Y.; Okada, A.; Kurauchi, T.; Kamigaito, O. Synthesis of nylon 6-clay hybrid. J. Mater. Res. 1993, 8, 1179-1184. [CrossRef]

2. Usuki, A.; Kawasumi, M.; Kojima, Y.; Fukushima, Y.; Okada, A.; Kurauchi, T.; Kamigaito, O. Mechanical properties of nylon 6-clay hybrid. J. Mater. Res. 1993, 8, 1185-1189. [CrossRef]

3. Rafiee, M.A.; Rafiee, J.; Wang, Z.; Song, H.; Yu, Z.Z.; Koratkar, N. Enhanced Mechanical Properties of Nanocomposites at Low Graphene Content. ACS Nano 2009, 3, 3884-3890. [CrossRef] [PubMed]

4. Chan, C.M.; Wu, J.; Li, J.X.; Cheung, Y.K. Polypropylene/calcium carbonate nanocomposites. Polymer 2002, 43, 2981-2992. [CrossRef]

5. Gilman, J.W. Flammability and thermal stability studies of polymer layered-silicate (clay) nanocomposites. Appl. Clay Sci. 1999, 15, 31-49. [CrossRef]

6. Yong, T.; Yuan, H.; Lei, S.; Ruowen, Z.; Zhou, G.; Zuyao, C.; Weicheng, F. Preparation and thermal stability of polypropylene/montmorillonite nanocomposites. Polym. Degrad. Stab. 2003, 82, 127-131.

7. Laoutid, F.; Bonnaud, L.; Alexandre, M.; Cuesta, J.M.L.; Dubois, P. New prospects in flame retardant polymer materials: From fundamentals to nanocomposites. Mater. Sci. Eng. R 2009, 63, 100-125. [CrossRef]

8. Du, M.; Guo, B.; Jia, D. Thermal stability and flame retardant effects of halloysite nanotubes on poly(propylene). Eur. Polym. J. 2006, 42, 1362-1369. [CrossRef]

9. Du, F.; Scogna, R.C.; Zhou, W.; Brand, S.; Fischer, J.E.; Winey, K.I. Nanotube Networks in Polymer Nanocomposites: Rheology and Electrical Conductivity. Macromolecules 2004, 37, 9048-9055. [CrossRef]

10. Tjong, S.C.; Liang, G.D.; Bao, S.P. Electrical behavior of polypropylene/multiwalled carbon nanotube nanocomposites with low percolation threshold. Scr. Mater. 2007, 57, 461-464. [CrossRef]

11. Thomassin, J.M.; Pardoen, C.J.T.; Bailly, C.; Huynen, I.; Detrembleur, C. Polymer/carbon based composites as electromagnetic interference (EMI) shielding materials. Mater. Sci. Eng. $R$ 2013, 74, 211-232. [CrossRef]

12. Li, N.; Huang, Y.; Du, F.; He, X.; Lin, X.; Gao, H.; Ma, Y.; Li, F.; Chen, Y.; Eklund, P.C. Electromagnetic Interference (EMI) Shielding of Single-Walled Carbon Nanotube Epoxy Composites. Nano Lett. 2006, 6 , 1141-1145. [CrossRef] [PubMed] 
13. Sanchez, C.; Lebeau, B.; Chaput, F.; Boilot, J.P. Optical Properties of Functional Hybrid Organic-Inorganic Nanocomposites. Adv. Mater. 2003, 15, 1969-1994. [CrossRef]

14. Paiva, L.B.; Morales, A.R.; Guimaraes, T.R. Structural and optical properties of polypropylenemontmorillonite nanocomposites. Mater. Sci. Eng. A 2007, 447, 261-265. [CrossRef]

15. Bharadwaj, R.K. Modeling the Barrier Properties of Polymer-Layered Silicate Nanocomposites. Macromolecules 2001, 34, 9189-9192. [CrossRef]

16. Cui, Y.; Kundalwal, S.I.; Kumar, S. Gas barrier performance of graphene/polymer nanocomposites. Carbon 2016, 98, 313-333. [CrossRef]

17. Saujanya, C.; Radhakrishnan, S. Structure development and crystallization behaviour of PP/nanoparticulate composite. Polymer 2001, 42, 6723-6731. [CrossRef]

18. Asuka, K.; Liu, B.; Terano, M.; Nitta, K. Homogeneously Dispersed Poly(propylene)/SiO $\mathrm{S}_{2}$ Nanocomposites with Unprecedented Transparency. Macromol. Rapid Commun. 2006, 27, 910-913. [CrossRef]

19. Yeo, S.Y.; Lee, H.J.; Jeong, S.H. Preparation of nanocomposite fibers for permanent antibacterial effect. J. Mater. Sci. 2003, 38, 2143-2147. [CrossRef]

20. Calvo, M.E.; Smirnov, J.R.C.; Míguez, H. Novel approaches to flexible visible transparent hybrid films for ultraviolet protection. J. Polym. Sci. Part B Polym. Phys. 2012, 50, 945-956. [CrossRef]

21. Mazrouaa, A.M. Polypropylene Nanocomposites. In Polypropylene, 1st ed.; Dogan, F., Ed.; InTech: Rijeka, Croatia, 2012; Volume 14, pp. 265-287.

22. Palza, H.; Vergara, R.; Zapata, P. Composites of polypropylene melt blended with synthesized silica nanoparticles. Compos. Sci. Technol. 2011, 71, 535-540. [CrossRef]

23. Bikiaris, D.; Papageorgiou, G.; Pavlidou, E.; Vouroutzis, N.; Palatzoglou, P.; Karayannidis, G. Preparation by melt mixing and characterization of isotactic polypropylene $/ \mathrm{SiO}_{2}$ nanocomposites containing untreated and surface-treated nanoparticles. J. Appl. Polym. Sci. 2006, 100, 2684-2696. [CrossRef]

24. Kalaitzidou, K.; Fukushima, H.; Drzal, L.T. A new compounding method for exfoliated graphitepolypropylene nanocomposites with enhanced flexural properties and lower percolation threshold. Compos. Sci. Technol. 2007, 67, 2045-2051. [CrossRef]

25. Scharlach, K.; Kaminsky, W. New Polyolefin-Nanocomposites by In Situ Polymerization with Metallocene Catalysts. Macromol. Symp. 2008, 261, 10-17. [CrossRef]

26. Guo, N.; DiBenedetto, S.A.; Kwon, D.K.; Wang, L.; Russell, M.T.; Lanagan, M.T.; Facchetti, A.; Marks, T.J. Supported Metallocene Catalysis for In Situ Synthesis of High Energy Density Metal Oxide Nanocomposites. J. Am. Chem. Soc. 2007, 129, 766-767. [CrossRef] [PubMed]

27. Balhoul, W.; Legaré, V.B.; David, L.; Cassagnau, P. Morphology and viscoelasticity of $\mathrm{PP} / \mathrm{TiO}_{2}$ nanocomposites prepared by in situ sol-gel method. J. Polym. Sci. Part B Polym. Phys. 2010, 48, 1213-1222. [CrossRef]

28. Kaneko, K.; Yadav, N.; Takeuchi, K.; Maira, B.; Terano, M.; Taniike, T. Versatile strategy for fabrication of polypropylene nanocomposites with inorganic network structures based on catalyzed in-situ sol-gel reaction during melt mixing. Compos. Sci. Technol. 2014, 102, 120-125. [CrossRef]

29. Xu, Z.; Gao, C. In situ Polymerization Approach to Graphene-Reinforced Nylon-6 Composites. Macromolecules 2010, 43, 6716-6723. [CrossRef]

30. Cheng, H.K.F.; Sahoo, N.G.; Tan, Y.P.; Pan, Y.; Bao, H.; Li, L.; Chan, S.H.; Zhao, J. Poly(vinyl alcohol) Nanocomposites Filled with Poly(vinyl alcohol)-Grafted Graphene Oxide. ACS Appl. Mater. Interfaces 2012, 4, 2387-2394. [CrossRef] [PubMed]

31. Zhang, M.Q.; Rong, M.Z.; Yu, S.L.; Wetzel, B.; Friedrich, K. Effect of particle surface treatment on the tribological performance of epoxy based nanocomposites. Wear 2002, 253, 1086-1093. [CrossRef]

32. Goel, V.; Pietrasik, J.; Dong, H.; Sharma, J.; Matyjaszewski, K.; Krishnamoorti, R. Structure of Polymer Tethered Highly Grafted Nanoparticles. Macromolecules 2011, 44, 8129-8135. [CrossRef]

33. Zhu, A.; Cai, A.; Zhou, W.; Shi, Z. Effect of flexibility of grafted polymer on the morphology and property of nanosilica/PVC composites. Appl. Surf. Sci. 2008, 254, 3745-3752. [CrossRef]

34. Lin, N.; Chen, G.; Huang, J.; Dufresne, A.; Chang, P.R. Effects of polymer-grafted natural nanocrystals on the structure and mechanical properties of poly(lactic acid): A case of cellulose whisker-graft-polycaprolactone. J. Appl. Polym. Sci. 2009, 113, 3417-3425. [CrossRef]

35. Kumar, S.K.; Jouault, N.; Benicewicz, B.; Neely, T. Nanocomposites with Polymer Grafted Nanoparticles. Macromolecules 2013, 46, 3199-3214. [CrossRef] 
36. Wang, Z.M.; Hong, H.; Chung, T.C. Synthesis of Maleic Anhydride Grafted Polypropylene with High Molecular Weight Using Borane $/ \mathrm{O}_{2}$ Radical Initiator and Commercial PP Polymers. Macromolecules 2005, 38, 8966-8970. [CrossRef]

37. Rong, M.Z.; Zhang, M.Q.; Zheng, X.Y.; Zeng, H.M.; Friedrich, K. Improvement of tensile properties of nano-SiO $2 /$ PP composites in relation to percolation mechanism. Polymer 2001, 42, 3301-3304. [CrossRef]

38. Wu, C.L.; Zhang, M.Q.; Rong, M.Z.; Friedrich, K. Tensile performance improvement of low nanoparticles filled-polypropylene composites. Compos. Sci. Technol. 2002, 62, 1327-1340. [CrossRef]

39. Cai, L.F.; Huang, X.B.; Rong, M.Z.; Ruan, W.H.; Zhang, M.Q. Effect of grafted polymeric foaming agent on the structure and properties of nano-silica/polypropylene composites. Polymer 2006, 47, 7043-7050. [CrossRef]

40. Ma, C.G.; Rong, M.Z.; Zhang, M.Q.; Friedrich, K. Irradiation-induced surface graft polymerization onto calcium carbonate nanoparticles and its toughening effects on polypropylene composites. Polym. Eng. Sci. 2005, 45, 529-538. [CrossRef]

41. Castel, C.D.; Pelegrini, T.; Barbosa, R.V.; Liberman, S.A.; Mauler, R.S. Properties of silane grafted polypropylene/montmorillonite nanocomposites. Compos. Part A Appl. Sci. Manuf. 2010, 41, 185-191. [CrossRef]

42. Lin, O.H.; Akil, H.M.; Ishak, Z.A.M. Surface-activated nanosilica treated with silane coupling agents/polypropylene composites: Mechanical, morphological, and thermal studies. Polym. Compos. 2011, 32, 1568-1583. [CrossRef]

43. Umemori, M.; Taniike, T.; Terano, M. Influences of polypropylene grafted to $\mathrm{SiO}_{2}$ nanoparticles on the crystallization behavior and mechanical properties of polypropylene $/ \mathrm{SiO}_{2}$ nanocomposites. Polym. Bull. 2012, 68, 1093-1108. [CrossRef]

44. Taniike, T.; Toyonaga, M.; Terano, M. Polypropylene-grafted nanoparticles as a promising strategy for boosting physical properties of polypropylene-based nanocomposites. Polymer 2014, 55, 1012-1019. [CrossRef]

45. Rong, M.Z.; Zhang, M.Q.; Zhang, Y.X.; Zeng, H.M.; Walter, R.; Friedrich, K. Structure-property relationships of irradiation grafted nano-inorganic particle filled polypropylene composites. Polymer 2001, 42, 167-183. [CrossRef]

46. Bartholome, C.; Beyou, E.; Bourgeat-Lami, E.; Cassagnau, P.; Chaumont, P.; David, L.; Zydowicz, N. Viscoelastic properties and morphological characterization of silica/polystyrene nanocomposites synthesized by nitroxide-mediated polymerization. Polymer 2005, 46, 9965-9973. [CrossRef]

47. Han, C.J.; Lee, M.S.; Byun, D.J.; Kim, S.Y. Synthesis of Hydroxy-Terminated Polyethylene via Controlled Chain Transfer Reaction and Poly(ethylene-b-caprolactone) Block Copolymer. Macromoleclues 2002, 35, 8923-8925. [CrossRef]

48. Naga, N.; Mizumura, K. Chain transfer reaction by trialkylaluminum $\left(\mathrm{AIR}_{3}\right)$ in the stereospecific polymerization of propylene with metallocene- $\mathrm{AIR}_{3} / \mathrm{Ph}_{3} \mathrm{CB}\left(\mathrm{C}_{6} \mathrm{~F}_{5}\right)_{4}$. Polymer 1998, 39, 5059-5067. [CrossRef]

49. Yamada, K.; Hikosaka, M.; Toda, A.; Yamazaki, S.; Tagashira, K. Equilibrium Melting Temperature of Isotactic Polypropylene with High Tacticity: 1. Determination by Differential Scanning Calorimetry. Macromolecules 2003, 36, 4790-4801. [CrossRef]

50. Toda, A.; Taguchi, K.; Sato, K.; Nozaki, K.; Murayama, M.; Tagashira, K.; Konishi, M. Melting kinetics of it-polypropylene crystals over wide heating rates. J. Therm. Anal. Calorim. 2013, 113, 1231-1237. [CrossRef]

51. Lorenzo, A.T.; Arnal, M.L.; Müller, A.J.; Lin, M.C.; Chen, H.L. SAXS/DSC Analysis of the Lamellar Thickness Distribution on a SSA Thermally Fractionated Model Polyethylene. Macromol. Chem. Physic. 2011, 212, 2009-2016. [CrossRef]

52. Chen, S.H.; Su, C.H.; Su, A.C.; Sun, Y.S.; Jeng, U.; Chen, S.A. Gibbs-Thomson analysis of crystalline poly(9,9-di-n-octyl-2,7-fluorene). J. Appl. Crystallogr. 2007, 40, 573-576. [CrossRef]

53. Liu, Y.; Bo, S.; Zhu, Y.; Zhang, W. Determination of molecular weight and molecular sizes of polymers by high temperature gel permeation chromatography with a static and dynamic laser light scattering detector. Polymer 2003, 44, 7209-7220. [CrossRef]

54. Fukuyama, Y.; Kawai, T.; Kuroda, S.; Toyonaga, M.; Taniike, T.; Terano, M. The effect of the addition of polypropylene grafted $\mathrm{SiO}_{2}$ nanoparticle on the crystallization behavior of isotactic polypropylene. J. Therm. Anal. Calorim. 2013, 113, 1511-1519. [CrossRef] 
55. Loos, J.; Hückert, A.; Petermann, J. On the crystallization behavior of cold-drawn syndiotactic polypropylene. Colloid Polym. Sci. 1996, 274, 1006-1011. [CrossRef]

56. Vladimirov, V.; Betchev, C.; Vassiliou, A.; Papageorgiou, G.; Bikiaris, D. Dynamic mechanical and morphological studies of isotactic polypropylene/fumed silica nanocomposites with enhanced gas barrier properties. Compos. Sci. Technol. 2006, 66, 2935-2944. [CrossRef]

57. Ranade, A.; Nayak, K.; Fairbrother, D.; D'Souz, N.A. Maleated and non-maleated polyethylenemontmorillonite layered silicate blown films: Creep, dispersion and crystallinity. Polymer 2005, 46, 7323-7333. [CrossRef]

58. Stern, C.; Frick, A.; Weickert, G. Relationship between the structure and mechanical properties of polypropylene: Effects of the molecular weight and shear-induced structure. J. Appl. Polym. Sci. 2007, 103, 519-533. [CrossRef]

59. Garcia, M.; Vliet, G.; Jahin, S.; Schrauwen, B.A.G.; Sarkissov, A.; Zyl, W.E.; Boukamp, B. Polypropylene $/ \mathrm{SiO}_{2}$ Nanocomposites with Improved Mechanical Properties. Rev. Adv. Mater. Sci. 2004, 2, 169-175.

60. McNally, T.; McShane, P.; Nally, G.M.; Murphy, W.R.; Cook, M.; Miller, A. Rheology, phase morphology, mechanical, impact and thermal properties of polypropylene/metallocene catalysed ethylene 1-octene copolymer blends. Polymer 2002, 43, 3785-3793. [CrossRef]

(C) 2016 by the authors; licensee MDPI, Basel, Switzerland. This article is an open access article distributed under the terms and conditions of the Creative Commons Attribution (CC-BY) license (http://creativecommons.org/licenses/by/4.0/). 